\title{
Transactions
}

Cite this: Dalton Trans., 2012, 41, 8215

www.rsc.org/dalton

PERSPECTIVE

\section{New catalysts with unsymmetrical $N$-heterocyclic carbene ligands}

\author{
Johanna Tornatzky, $\dagger$ Axel Kannenberg $\dagger$ and Siegfried Blechert* \\ Received 3rd February 2012, Accepted 5th April 2012 \\ DOI: $10.1039 / \mathbf{c} 2 \mathrm{dt30256j}$ \\ The importance of unsymmetrical $N$-heterocyclic carbenes (uNHCs) as ligands in metal-catalyzed \\ reactions is undeniable. While uNHCs show similar properties as compared with symmetrical NHCs, \\ dissymmetrization allows for further fine-tuning. The introduction of chelatization, hemilability, \\ bifunctionality, shielding effects, and chirality-transfer influences the catalyst's stability, reactivity, and \\ selectivity, thus offering access to tailor-made systems including mono- and multidentate uNHC ligands. \\ Based on selected examples, the structure-reactivity relationship of uNHCs employed in metal catalysts is \\ presented. The focus is on catalytically active complexes, which either offer access to new applications or \\ lead to significantly improved results in metal-catalyzed reactions.
}

\section{Introduction}

The exciting history of $\mathrm{N}$-heterocyclic carbenes (NHCs) began with the pioneering work of Wanzlick ${ }^{1}$ and Lappert ${ }^{2}$ and the isolation and identification of a stable NHC by Arduengo et al. in 1991. ${ }^{3}$ Their outstanding stability and excellent donating ability, due to their steric demand and the synergy of inductive and mesomeric effects of the heteroatom(s) in vicinity to the carbenic center, respectively, make NHCs attractive ligands, which had a

Institut für Chemie, Technische Universität Berlin, Straße des 17 Juni 135, D-10623 Berlin, Germany.E-mail: blechert@tu-berlin.de; Fax: +030 314 23619; Tel: +03031422255

$\dagger$ Both authors contributed equally to this work. great impact on the development of metal-catalyzed transformations. Extensive reviews covering NHC complexes in transition metal catalysis have been published within the last few years. ${ }^{4 a-n}$ In this perspective we report on the application of unsymmetrical NHCs (uNHCs) as ligands in metal-catalyzed reactions, where special performance has been noted. The motivation for designing new ligands of this particular type is based on the potential benefits regarding the reactivity and selectivity of their corresponding metal complexes. The electronic and structural parameters of non-symmetrical ligands directly influence the catalyst's performance. By varying the number and the location of the heteroatoms in the core structure of the NHC (e.g. triazol-derived or abnormally bound NHCs), dissymmetry can be generated. The variation of the substituents bound to the

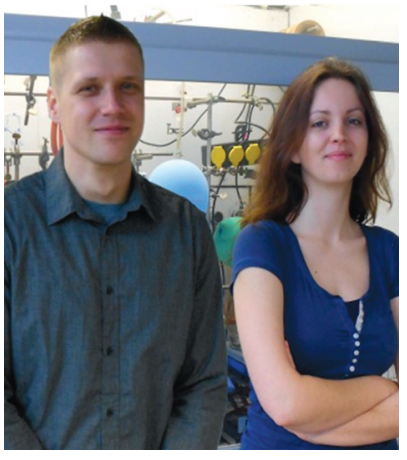

Axel Kannenberg and

Johanna Tornatzky
Axel Kannenberg was born in Berlin (Germany) in 1980. He studied chemistry at the Berlin University of Technology and received his diploma in 2008. In 2009 he started his Ph.D. studies under the supervision of Prof. S. Blechert, focusing on development of chiral $\mathrm{NHC}-$ ruthenium complexes and investigation of their performance in olefin metathesis.

Johanna Tornatzky was born in 1983 in Filderstadt (Germany). She received her diploma in 2008 at the Berlin University of Technology, where she is presently working on her Ph.D. including stereocontrolled ring-rearrangement metathesis processes in natural product synthesis under the supervision of Prof. S. Blechert.

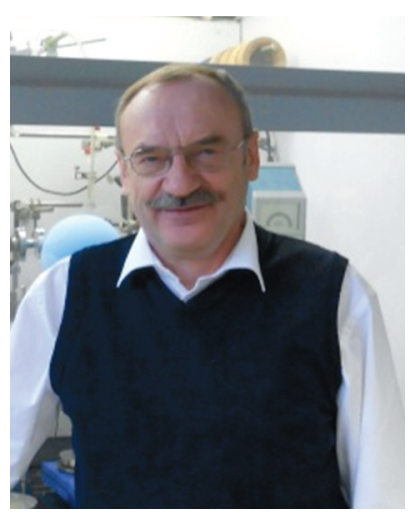

Siegfried Blechert
Siegfried Blechert was born in Aalborg (Denmark) in 1946. He received his Ph.D. from the University of Hannover (Germany) under Prof. E. Winterfeldt in 1974. After a post-doctoral period (19741980) in Hannover and Gifsur-Yvette (France) (1981) he became lecturer in Organic Chemistry in Hannover and Full Professor of Organic Chemistry in 1986 (University of Bonn). Since 1990 he has been working at the Berlin University of Technology as Full Professor. His research interests include development of (asymmetric) catalysts for metathesis and hydroamination reactions, application of these methodologies in natural product syntheses, organocatalysis, and the integration of semi-conducting materials in oxidative processes. 
nitrogen atoms and to the backbone can also lead to uNHCs. Further, the introduction of chelating donors can give rise to unsymmetrical bi- and tridentate ligands. While focusing on recent developments starting from 2009, in this perspective mono-, bi- and tridentate uNHCs are covered, and the structurereactivity relationship of their achiral and chiral metal complexes is discussed. For easier understanding of the location of substituents within the uNHCs, the nitrogen atoms are labeled as $N$ and $N^{\prime}$.

\section{Metal catalysts with monodentate uNHCs}

Monodentate achiral uNHCs have predominantly been used for $\mathrm{Cu}-, \mathrm{Pd}-, \mathrm{Au}-$ and Ru-catalysts. Combining a stabilizing bulky $N$-substituent with a $N^{\prime}$-moiety of flexible sterics, influencing the reactivity of the complex and thus opening access to the metal center, offers novel perspectives in metal-mediated catalysis. As an example, Grubbs and coworkers investigated the Ru-based olefin metathesis precatalyst $\mathbf{1}$, showing high chemoselectivity towards the ethenolysis of methyl oleate (Scheme 1). ${ }^{5}$ At catalyst loadings of only $0.05 \mathrm{~mol} \%$ and 10 bar ethylene, terminal alkenes as the desired products can be obtained in up to $95 \%$ selectivity. This represents a valuable method to convert fatty acids, as derived from renewable biomass, to synthetically useful products on a large scale. The sterically charged uNHC is responsible for the chemoselectivity of the catalyst, thus preventing (homo-) cross metathesis reactions of the terminal alkenes, in order to improve the selectivity in favor of the degenerative metathesis event. However, the presence of a methylidene species is required, which mediates the cleavage of the internal double bond. ${ }^{6}$ While methylidene complexes derived from commonly employed metathesis precatalysts are often unstable, thus restricting product selectivity and conversion, uNHC-containing $\mathrm{Ru}-$ methylidene complexes exhibit an unusually high stability.

In 2010, the group of Hashmi published the elegant synthesis of Pd-imidazolinylidene complexes related to $\mathbf{2}$ allowing the variation of the substitution pattern at all four positions of the uNHC (Scheme 2). ${ }^{7 a-c}$ These complexes could be prepared in only one step from $\mathrm{Pd}$-isonitriles: ${ }^{7 a}$ a secondary amine attacks the carbon atom of the activated isonitrile in presence of a base

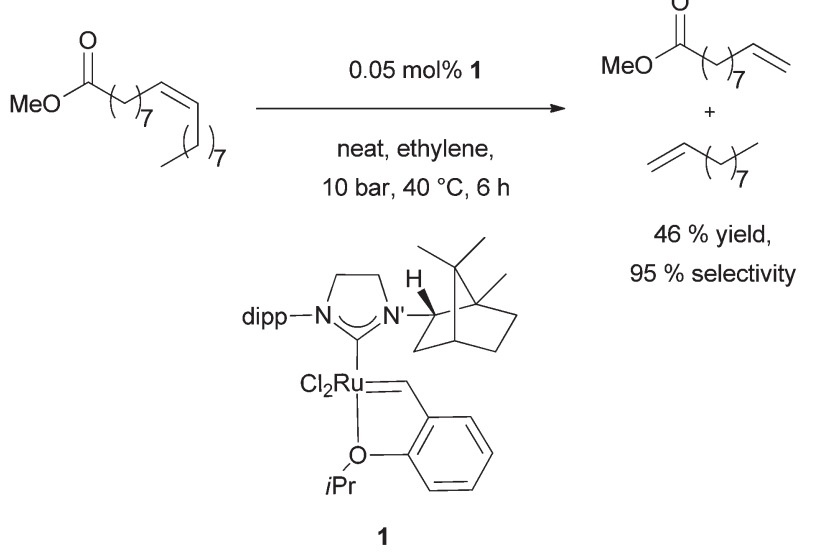

Scheme 1 Ethenolysis of methyl oleate promoted by 1 (dipp = 2,6diisopropylphenyl). and the metal precatalyst $\mathbf{2}$ is formed via subsequent cyclization of the anionic intermediate. This procedure is efficient and also displays a promising synthetic access towards unsymmetrical $\mathrm{Au}-$ and Pt-based compounds bearing five- and six-membered ${ }^{8}$ uNHCs. Sterically demanding boronic acids were successfully coupled with aryl bromides and with even more challenging chlorides in a Suzuki reaction. The transformation is mediated by using catalyst loadings down to $0.1 \mathrm{~mol} \%$, at ambient temperature, in technical grade solvent, and without prior degassing. Screening experiments revealed $\mathbf{2}$ as the most successful precatalyst for the Pd-mediated coupling reaction in this series, showing sufficient stability combined with enhanced reactivity. The installation of dipp as a bulky $N$-substituent $\mathrm{R}^{1}$ was of particular importance for the stability of the complex, especially in combination with the phenyl group in the backbone $\left(\mathrm{R}^{4}\right)$, which exerts a steric influence on the $N$-aryl group. This substitution pattern leads to enhanced rigidity, which is assumed to improve the reductive elimination step in the coupling reaction. A clear correlation between the reactions outcome and the size of the aliphatic ring system was found ${ }^{7 b}$ for example, the use of a 15 -membered ring for $\mathrm{R}^{2}$ resulted in enhanced yields. The flexibility of this aliphatic ring allows the substrate to enter the metal's coordination site easily, and the hydrophobic effect facilitates oxidative addition.

Ghosh introduced the palladium complex 3 (Fig. 1) as a precatalyst for $\mathrm{C}-\mathrm{C}$ bond formation reactions of the Hiyama- and Sonogashira-type. ${ }^{9}$ The Hiyama coupling in a mixed aqueous medium under aerobic and fluoride-free conditions was mediated by 3 in good to excellent yields. In addition, 3 represents the first example of a well-defined uNHC-based precatalyst that is active in a Sonogashira reaction at air under both copper- and amine-

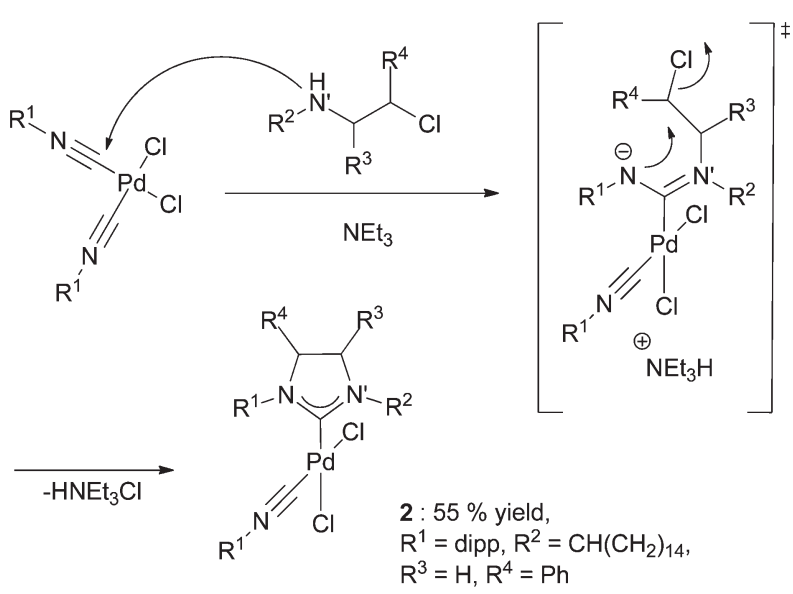

Scheme 2 Variable synthesis of Pd-uNHC complexes in one step.

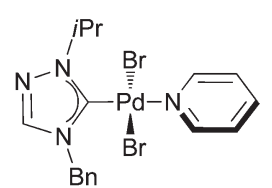

3

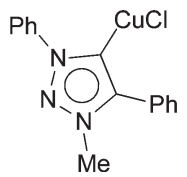

4
Fig. 1 Catalysts 3 and $\mathbf{4}$ bearing triazol-based uNHC ligands. 
free conditions. Apart from this fact, short reaction times are achieved, thus demonstrating the high efficiency and robustness of this catalyst due to the electron donating properties of the triazol-based ligand. The latter also causes a strong transinfluence and therefore weakens the pyridyl-metal ligation. ${ }^{10}$ By cleavage of this "throw away" ligand a highly catalytically active species is generated. Control experiments in the absence of the uNHC revealed that the influence of the carbene results in significantly enhanced product yields.

The influence of the 1,2,3-triazole-derived uNHCs incorporated in well-defined copper(I) species such as 4 (Fig. 1) was investigated by the group of Fukuzawa in the Huisgen $[3+2]$ cycloaddition. ${ }^{11,12}$ The coupling of benchmark substrates, e.g. benzyl azide and phenyl acetylene, under air in the absence of a solvent with catalyst loadings of $1.0 \mathrm{~mol} \%$ resulted in full conversion after $90 \mathrm{~min}$ at room temperature. In comparison with the symmetrical $\mathrm{Cu}-\mathrm{NHC}$ complex $\mathrm{CuCl}(\mathrm{IMes}), 4$ exhibits enhanced catalytic activity. This demonstrates the excellent $\sigma$ donor character of the abnormally bound triazole-based uNHC ligand, which activates the $\mathrm{Cu}(\mathrm{I})$ center. The sterically least demanding $\mathbf{4}$ is the most efficient precatalyst in the series of investigated copper systems. Moreover, 4 successfully mediates the cycloaddition of hindered alkynes with bulky azides, which is a particularly challenging click reaction. ${ }^{13}$

\section{Monodentate uNHCs in asymmetric metal catalysis}

The efficient transfer of chirality from monodentate asymmetric uNHCs to the coordination sphere of the metal center is challenging. The stereogenic center can be located, for example, in the uNHCs backbone or in its side chain, and the latter concept was applied by the group of McQuade in Cu-catalyst 5 (Scheme 3). ${ }^{14}$ A planar imidazoquinazoline serves as the core element of the six-membered uNHC, ${ }^{15 a, b}$ and is combined with a stabilizing 2,4,6-trimethylphenyl (also mesityl or Mes) group. The stereocenter in the $N^{\prime}$-substituent is in proximity of the metal's coordination sphere. Tethering this group to the uNHC backbone results in additional rigidity, thus enhancing the transfer of chirality. The corresponding $\mathrm{Cu}$-species $\mathbf{5}$ constitutes the first example of a catalyst bearing this type of ligand efficiently inducing enantioselectivity in a $\beta$-borylation reaction (Scheme 3).
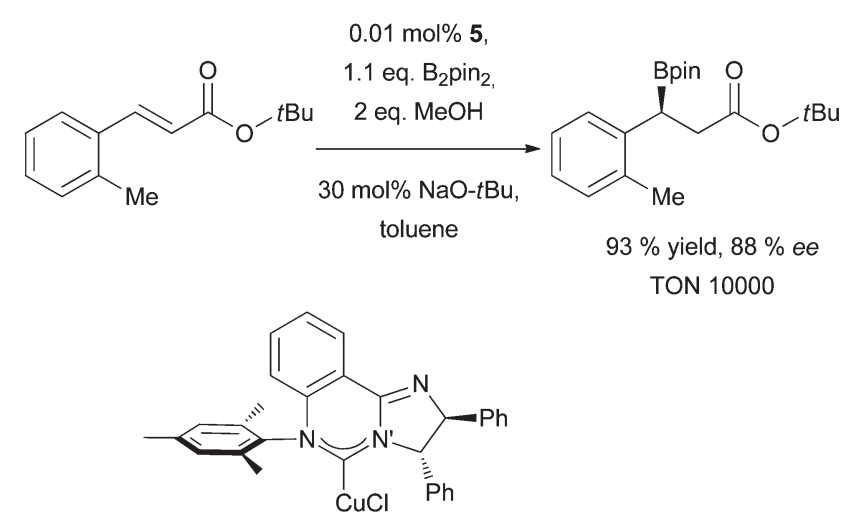

5

Scheme 3 Cu-catalyst 5 bearing a 6-uNHC active in an asymmetric $\beta$-borylation.
This result indicates that the ligand provides a beneficial electronic effect. In a substitution reaction involving allylic ethers and boron-based nucleophiles, it was demonstrated that this complex provides superior activity compared with $\mathrm{Cu}$-systems bearing symmetrical ligands. ${ }^{16}$

Another concept for the induction of chirality in monodentate uNHCs is an asymmetric backbone substitution. The challenge, however, is the efficient transfer of the chiral information to the metal center. This goal can be achieved by the use of $N$-aryl substituents, which cannot rotate and which are significantly twisted due to steric repulsions with the stereogenic groups. ${ }^{17 a-d}$ The induced conformational change provides a defined substrate preorientation in the coordination sphere that is essential for enantiodiscrimination. Hoveyda investigated the catalytic activity of unsymmetrical copper complexes derived from 6-type imidazolium salts, which carry one dissymmetric $N$-aryl substituent and one symmetric $N^{\prime}$-aryl substituent (Scheme 4). ${ }^{18}$ In comparison to $\mathrm{Cu}$-species with bidentate NHCs investigated therein, these catalysts showed good activity and improved selectivity in the unprecedented conjugated arylation of cyclic enones using organosilanes as nucleophiles. Especially their higher functional group tolerance and the low sensitivity against oxygen and moisture as compared with commonly used organometallic compounds makes the silicon-based reagents interesting nucleophiles. The reactivity and selectivity of the metal-based compounds was determined by variation of both the $N$ - and $N^{\prime}$ aryl moiety. Regarding the symmetrical $N^{\prime}$-substituent, a correlation between the size of the attached groups and a diminished substrate approach was observed. Sterically demanding substituents lead to a decreased rate of formation of the required $\mathrm{Cu}$-aryl species as well as limited substrate coordination, thus reducing the reactivity. The disubstituted backbone carries the chiral information, which is transferred to the metal center via the neighboring dissymmetric $N$-aryl group. The size of the meta-substituent incorporated in this $N$-aryl moiety was shown to play an important role for the enantiodiscrimination, since it regulates the orientation of the coordinating enone substrate; the tert-butyl group revealed to be an ideal meta-substituent in the unsymmetrical $\mathrm{N}$-aryl group. An increase of the size of the ortho-substituent diminishes the selectivity of the reaction due to the steric

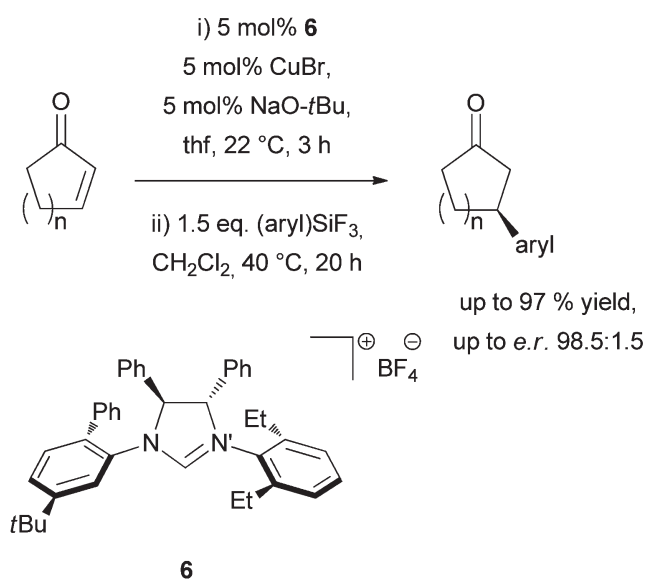

Scheme 4 Chiral uNHC precursor 6 employed in a copper-mediated Michael addition. 


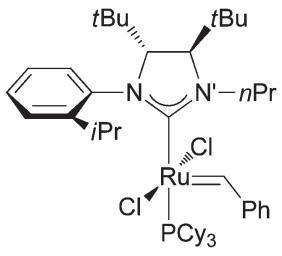

7

Fig. 2 Ru-catalyst 7 featuring a chiral monodentate uNHC.

repulsion with the NHC's backbone, thus leading to an unfavorable change in conformation. 6 was shown to be optimal for the Michael addition of alkenyl- and arylsilylfluorides to cyclic enones with up to $97 \%$ ee (Scheme 4). ${ }^{18}$

A modified catalyst was found to promote the allylation of imines using allyl boronates; ${ }^{19}$ the employed uNHC bears two different unsymmetrically substituted $N$ - and $N^{\prime}$-aryl moieties, and the formed complexes feature excellent performance in the above mentioned reaction, compared to bidentate $\mathrm{Cu}-\mathrm{NHC}$ systems and catalysts related to $\mathbf{6}$. The enhanced enantioselectivities may be attributed to the twist of the 2,4-disubstituted $N^{\prime}$ aryl moiety around the $\mathrm{N}-\mathrm{C}$ bond, lifting the resident orthomethyl group to facilitate the substrate coordination.

uNHCs with asymmetric disubstituted backbones are also used in ruthenium complexes that are active in metathesis reactions. The group of Collins recently generated catalysts of type $7^{17 c, 21}$ by modifying the chiral Grubbs catalyst (Fig. 2). ${ }^{17 d}$ The $N^{\prime}$-aryl group in the NHC was exchanged for an alkyl moiety. This modification resulted in diminished stability ${ }^{20}$ but enhanced reactivity due to the low steric impact on the metal center. The use of n-propyl instead of methyl for the $N^{\prime}$-alkyl moiety gave access to a complex of slightly improved stability. The transfer of the chiral information from the backbone to the metal center is induced by a conformational change of the $N$-aryl substituent, which results in promising enantioselectivities in the desymmetrisation of meso-trienes in the asymmetric ring-closing metathesis (ARCM). ${ }^{17 c, 21}$

By using uNHCs with monosubstituted backbones, Blechert and coworkers have designed complexes that exhibit high stability and reactivity at the same time, ${ }^{17 a, b}$ a goal that is in general difficult to achieve. ${ }^{22}$ Moreover, an ideal chirality transfer to the coordination sphere of the ruthenium center was realized. Precatalyst $\mathbf{8}$ was prepared by using readily available L-valine as the starting material (Scheme 5). ${ }^{17 b}$ In the first step, the unsymmetrical $N$-aryl group is introduced under Buchwald-Hartwig conditions generating 9. An additional three steps afford sulfamidate $\mathbf{1 0}$ in $59 \%$ yield, ${ }^{23}$ and the imidazolium salt $\mathbf{1 1}$ is generated via three further steps. After deprotonation, 8 was obtained by ligand exchange on the Hoveyda I precatalyst. The introduction of various backbone substituents can be easily accomplished by using the appropriate chiral starting material. Moreover, the route is very flexible with regard to the possible $N$-, $N^{\prime}$-substituents, thus offering access to a family of new asymmetric uNHC ligands.

In contrast to 7, complex 8 bears two different $N$-aryl groups, which increase the stability of the catalyst. The mesityl group was introduced as a bulky $N^{\prime}$-aryl moiety, wherein the ortho-substitutions prevent catalyst deactivation. ${ }^{24 a, b}$ Due to the lack of a

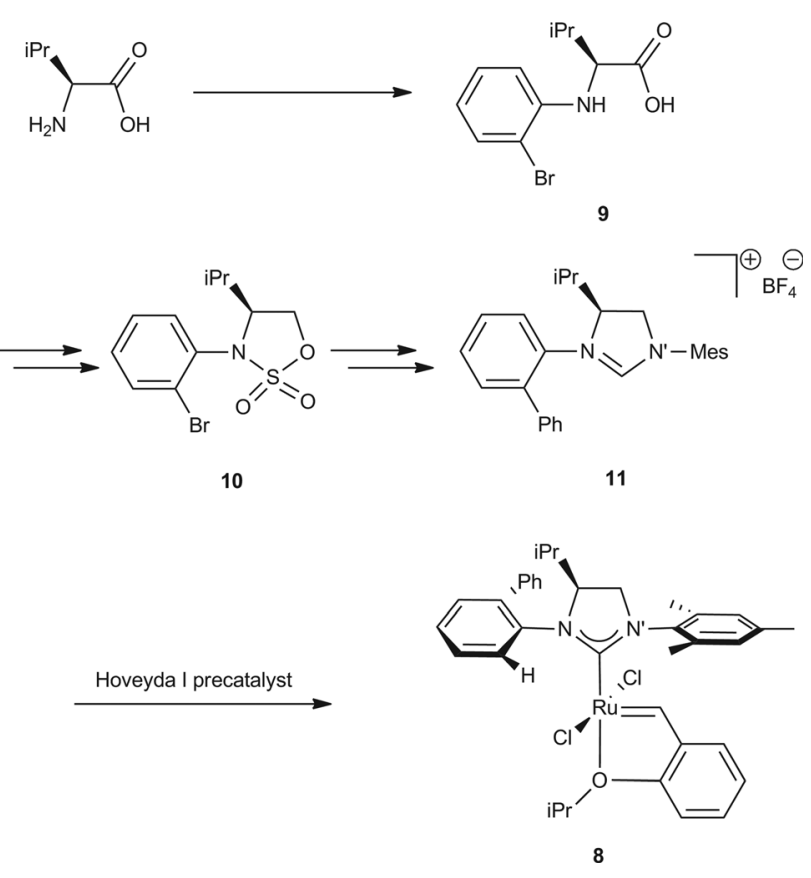

Scheme 5 Synthesis of $\mathbf{8}$ starting from L-valine.

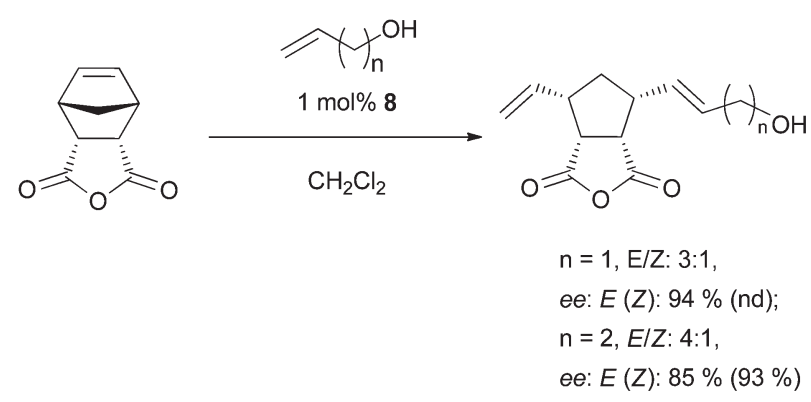

Scheme 6 AROCM reactions with allyl- and homoallyl alcohol as cross partner employing $\mathbf{8}(\mathrm{nd}=$ not determined).

second substituent in the backbone, the mesityl group adopts a coplanar alignment with respect to the uNHC. Consequently, steric shielding of the active center, which would diminish the catalyst reactivity, is avoided. The dissymmetric $N$-aryl substituent provides optimal chirality transfer from the backbone to the metal center. The well-balanced combination of substituents in this particular $\mathrm{uNHC}$ ligand leads to an optimal twist of the dissymmetric $N$-aryl group, resulting in superior performance of the metathetically active species. The catalytic behavior of $\mathbf{8}$ was investigated in an ARCM reaction. The addition of styrenes to the reaction mixture results in decreased reaction times and constantly good ee's. In asymmetric ring-opening cross-metathesis reactions (AROCM) employing norbornene derivatives and styrene as a cross partner, ee's of up to $93 \%$ and superior $E / Z$ ratios of up to $30: 1$ were obtained. In contrast, the use of a chiral $\mathrm{C}_{2}$-symmetrical catalyst did not result in any enantioselectivity and only poor $E / Z$ ratios were obtained. ${ }^{17 d}$ The reaction scope was extended to the application of other, more challenging cross partners (Scheme 6). ${ }^{25}$ The introduction of allyl alcohols, homoallyl alcohols, and allyl boronic esters successfully yielded the corresponding AROCM products with high ee's up to $94 \%$, 


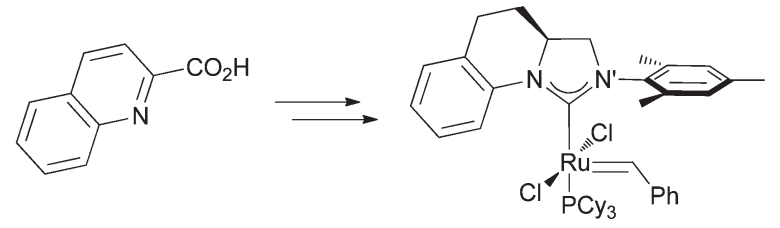

quinolinic acid

12

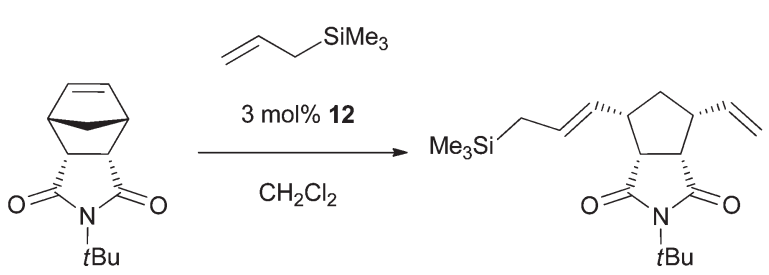

$E / Z: 2: 1$

ee: $E(Z): 98 \%(92 \%)$

Scheme 7 Chiral Ru-precatalyst $\mathbf{1 2}$ derived from quinolinic acid, active in AROCM reactions.

thus opening access to functionalized structures, useful for subsequent reactions. The superior activity of $\mathbf{8}$ allows for asymmetric metathesis reactions even at temperatures down to $-10{ }^{\circ} \mathrm{C} .{ }^{17 b}$ In addition, the high reactivity enables the use of very low catalyst loadings of down to $0.05 \mathrm{~mol} \%$. The precatalyst revealed a high stability, no sign of decomposition was observed even after 12 days at $40{ }^{\circ} \mathrm{C}$ in $\mathrm{CD}_{2} \mathrm{Cl}_{2}$.

Another complex that shows structural similarities with $\mathbf{8}$ such as the stabilizing coplanar $N^{\prime}$-mesityl group and the asymmetric monosubstituted backbone is $\mathbf{1 2}$, that can be efficiently synthesized from quinolinic acid (Scheme 7). ${ }^{17 a}$ However, in the latter complex the chiral center is rigidly tethered to the $\mathrm{N}$-aryl moiety. Thus, a large twist around the $N$-aryl bond is caused, forcing the arene into the coordination sphere of the ruthenium center. The increased steric demand affects an efficient chirality transfer from the backbone to the metal center, thus enhancing enantioselectivity. 12 was employed in the AROCM reaction of meso-norbornenes, using styrenes as cross-partners amongst others. The reaction with styrene yields the products in high $E$ selectivities and excellent ee's. The use of a chiral symmetrical catalyst shows significantly lower enantiomeric ratios in this reaction. ${ }^{17 d}$ The use of allyl silanes as cross-partners is unprecedented and opens access to diverse subsequent synthetic manipulations. For selected substrates, although in general more challenging, ${ }^{26 a-c}$ an elevated $Z$-selectivity is observed when 12 is used as the catalyst. Moreover, an excellent enantiodiscrimination is achieved (Scheme 7); this observation is most probably a consequence of the fixed, $N$-aryl unit, which is not able to rotate. Additionally, the ee values for both $E$ - and $Z$-isomers are similar, and this fact can be attributed to the catalytically active species: the norbornene-derivative reacts with the $\mathrm{Ru}$-methylidene species, and this step determines the ee values of the products; subsequent cross metathesis defines the configuration of the double bond. ${ }^{17 d}$ In comparative experiments using a $\mathrm{C}_{2}$-symmetric chiral catalyst, different enantioselectivities for the $E / Z$ isomers were observed; this result is attributed to the $\mathrm{Ru}-$ benzylidene species that opens the norbornene, and thus determines

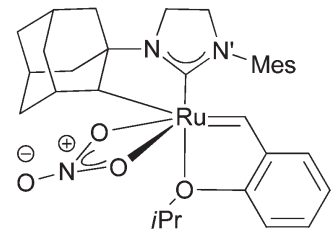

13

Fig. 3 Precatalyst 13, active in Z-selective olefin cross metathesis reactions.

the ee and the $E / Z$ ratio concurrently. ${ }^{17 d}$ The superior catalytic behavior of $\mathbf{8}$ and $\mathbf{1 2}$ in metathesis reactions demonstrates the advantage of the new ligand concept, which could therefore be of particular interest for other metal-catalyzed enantioselective reactions.

\section{Bidentate achiral uNHCs in metal catalysis}

In the bidentate uNHCs described here, carbon or hetero atoms constitute the additional neutral or anionic donors. Grubbs has investigated several robust, cyclometallated ruthenium compounds such as $\mathbf{1 3}$ (Fig. 3), which promote $Z$-selective olefin cross metathesis reactions. ${ }^{26 c, 27}$ Previously reported complexes with similar structural motifs were only isolated as decomposition products after $\mathrm{C}-\mathrm{H}$ insertion and do not exhibit any metathesis activity anymore. ${ }^{28}$ Systematic structural changes in the uNHC have demonstrated that the bulky and rigidly bound $\mathrm{N}$-adamantyl group is crucial for achieving a high amount of the thermodynamically disfavored Z-olefin. ${ }^{27}$ Mechanistic studies concerning Ru-complexes with this kind of bidentate ligands revealed that the formation of the $Z$-configured product is mainly a consequence of the steric repulsion by the $N$-adamantyl group. $^{26 b}$ However, due to secondary metathesis events, e.g. homocoupling, both the $Z$-selectivity (up to $91 \%$ ) and the formation of the desired product is reduced at increased conversion.

Thus, it is essential to gain insight into the kinetics of the reaction in order to obtain as much of the desired Z-product as possible. Moreover, the olefin cross metathesis reaction can be efficiently catalyzed by this type of complex with very low catalyst loadings, high temperatures are not required, and it is not necessary to work under reduced pressure or to exclude protic solvents.

Another class of cyclometallated complexes was introduced by Marinetti and coworkers. ${ }^{29}$ These Pt-based precatalysts were applied for the enantioselective cycloisomerization of nitrogentethered 1,6-enynes (Scheme 8). 14 was found to be the most suitable complex for this reaction, bearing a bidentate uNHC and a chiral monodentate phosphine ligand, combined with a weakly bound iodide ligand. The corresponding bicyclic product was obtained in up to $90 \%$ yield and with $96 \%$ ee. The introduction of a chiral phosphine in a trans position to the uNHC induces axial chirality. Therefore, $\mathbf{1 4}$ was isolated as a mixture of diastereomers. ${ }^{30}$ It is assumed that the catalytically active Pt(II) species is generated by the dissociation of the iodide. ${ }^{31}$ The comparison with an analogous but non-cyclometallated Pt-complex that is also able to mediate the cycloisomerization revealed that it is the restricted flexibility of the metallacycle in combination with the 

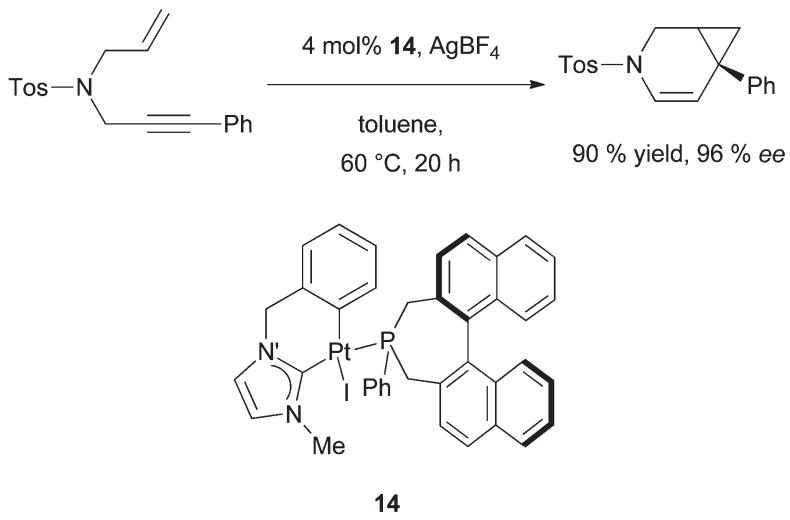

Scheme 8 Cycloisomerization reaction of 1,6-enynes promoted by 14 (Tos $=$ toluene sulfonyl).

chiral phosphine which is crucial for successful enantioinduction. Furthermore, also the reaction scope was extended to the desymmetrisation of prochiral dienynes mediated by 14 with good enantiodiscrimination. Another precatalyst that contains an additional stereogenic center within the UNHC, promotes the cycloisomerization of 1,6-enynes in promising yields but the selectivity is diminished. ${ }^{32}$ Obviously, the introduction of a further stereogenic center does not necessarily influence the enantiodiscrimination positively via a cooperative effect with the chiral monodentate phosphine.

The group of Mandal examined the halobridged palladium dimer 15 which was produced by cyclometallation and constitutes a prominent example featuring an abnormal uNHC (Fig. 4). ${ }^{33}$ Therein each palladium center is bound to the $\mathrm{C}(5)$-position of the carbene as well as to an ortho-aryl carbon atom, and two chlorides, thus leading to a square planar coordination geometry. 15 delivers excellent yields in the challenging coupling of aryl chlorides with phenylboronic acid at room temperature; only very low loadings down to $0.005 \mathrm{~mol} \%$ are required. It is the abnormal bonding mode to the uNHC that increases the electron density at the metal center substantially, ${ }^{34 a, b}$ thus enhancing the reactivity by promoting oxidative addition of the substrate. Furthermore $\mathbf{1 5}$ remains active for ten successive catalytic runs without any loss of activity, thus indicating a strong ligandmetal interaction, which prevents decomposition processes. This feature is attributed to the fact that both the aryl-metal bond and the abnormal ligated uNHC stabilize the metal species.

In 2010 Huynh and coworkers reported a rare example of an uNHC complex that exhibits an $S$-donor coordinating to a metal center (Fig. 4). ${ }^{35 a, b}$ These functionalities are electron rich and especially the sulfur-metal interaction is very strong and stabilizes the complex. As a consequence of the high electron density at the metal center in the dimeric compound 16, SuzukiMiyaura reactions of aryl bromides and aryl boronic acids are promoted with $0.001 \mathrm{~mol} \%$ catalyst loading in neat water. However, with such low loadings extended reaction times are necessary, and the prolonged initiation period is attributed to the above mentioned stabilizing effect of the chelating sulfur tether.

Bidentate uNHCs with a weaker coordinating heteroatom in the side chain allow access to a class of metal complexes that benefit from the hemilabile donor. ${ }^{36}$ This group can reversibly dissociate to generate the catalytically active species, which,
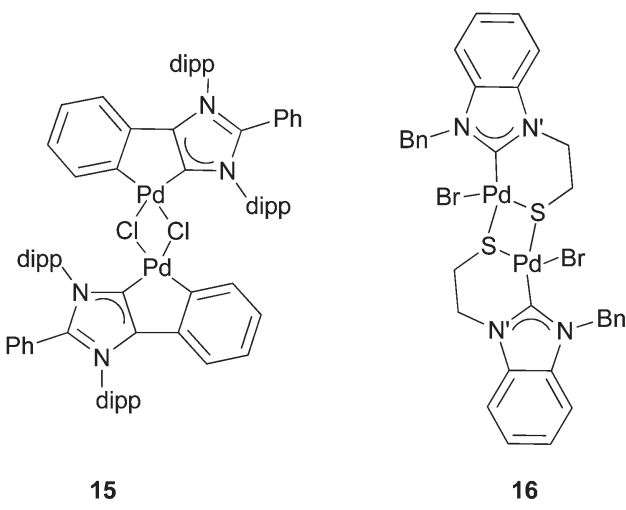

Fig. 4 Dimeric Pd-complexes $\mathbf{1 5}$ and $\mathbf{1 6}$

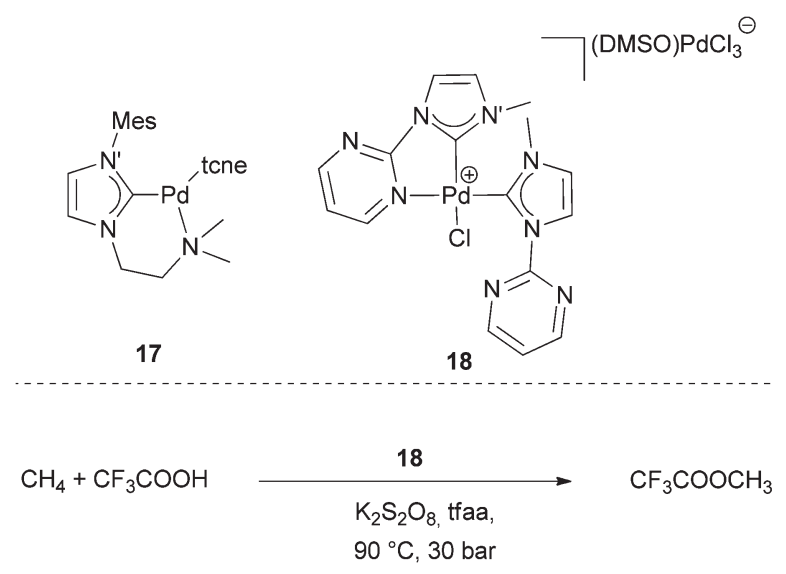

Scheme 9 Complexes $\mathbf{1 7}$ and $\mathbf{1 8}$ and methane activation mediated by Pd-catalyst 18 (tcne = tetracyano ethylene, tfaa = trifluoroacetic anhydride).

after product release, regenerates the precatalyst. The group of Elsevier explored a series of electron rich $\mathrm{Pd}(0)$-species of type 17 (Scheme 9) bearing a nitrogen donor incorporated in the $N$ substituent of the uNHC ligand that binds to the metal center. $^{37 a-e}$ The fact that all of these complexes incorporate an $N^{\prime}$-aryl group in the uNHC is important for the stability. In the context of their application in the semi hydrogenation of alkynes to produce $Z$-olefins using formic acid as a hydrogen source, the catalysts were investigated with regard to their reactivity and selectivity depending on the nature of the amine tether, using pyridyl-, pyrimidyl-, triazole-, picolyl- and tertiary amine (as in 17) groups. The selectivities significantly depend on the donor properties of the chelating moiety. In case of $N$-tethered donors that exhibit a lower affinity to bind to the metal center as compared to the alkene product, isomerization of the $Z$ - to the $E$ alkene and further reduction occurs after complete consumption of the alkyne, thus resulting in lower selectivities.

Only the tertiary amine has suitable donor properties to promote the semi hydrogenation in excellent $Z$-selectivities. ${ }^{37 a} \mathrm{~A}$ second feature of the chelating ligand is the inherent base functionality, which is strong enough to activate the hydrogen source. Additional bases are not needed, and this allows for suppressing isomerization reactions that are otherwise observed. 
<smiles>CC#CC#Cc1cccc(CC)c1N=C(Cl)c1cccc(CC)c1N</smiles>

20

$21,78 \%$ yield<smiles></smiles>

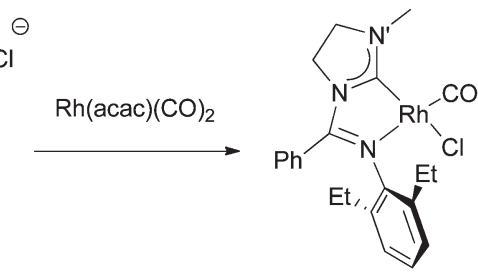

22, $70 \%$ yield

$19,95 \%$ yield

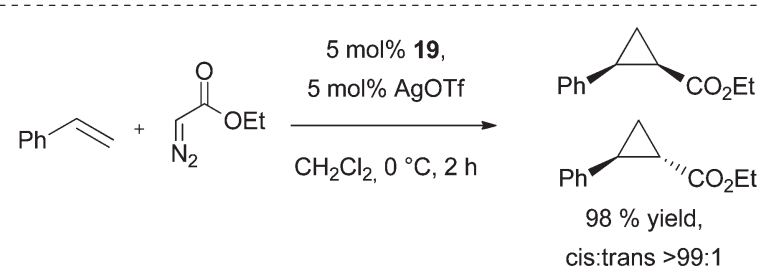

Scheme 10 Synthesis and catalytic application of 19.

The related Pd-based catalyst $\mathbf{1 8}$ was used by the group of Strassner for $\mathrm{C}-\mathrm{C}$ coupling reactions as well as methane activation where it displays extraordinary reactivity (Scheme 9). ${ }^{38 a, b}$ The latter reaction was carried out under harsh conditions, demonstrating the robustness of these bidentate metal compounds due to the chelating tether. The distortion of the square planar adjustment is a consequence of the smaller bite angle of the uNHC, decomposition of the complex by reductive elimination of the ligand is suppressed, a major problem encountered for systems that prefer this geometry. ${ }^{39}$

The chelating imine-functionalized uNHC ligand incorporated in catalyst 19 was successfully synthesized by Tilsit and coworkers in four steps starting from 2,6-diethyl aniline $\mathbf{2 0}$ (Scheme 10). ${ }^{40}$ The reaction of imidoyl chloride 21 with $N^{\prime}$ methyl imidazole generated the carbene precursor 22, which was transferred via ligand exchange to the rhodium source $\mathrm{Rh}(\mathrm{acac})-$ $(\mathrm{CO})_{2} .19$ was investigated in terms of the cis-selective cyclopropanation of alkenes with ethyl diazoacetate as a carbene precursor (Scheme 10).

Structural alterations of the arene linked to the imine revealed sterically demanding groups to be beneficial for an increased cis-trans ratio. No selectivity was observed for aryl groups lacking an ortho-substituent. The catalyst shows sensitivity concerning the steric hindrance of alkenes regarding selectivity and reactivity, thus limiting the substrate scope to terminal and some cyclic olefins.

\section{Bidentate chiral uNHCs in metal catalysis}

The chelating groups of bidentate uNHCs can also contribute to asymmetric induction, for example, if alcohols and amides are employed in chiral $\mathrm{N}$-substituents. Most of the mentioned metal complexes and active species, however, were not isolated or characterized via X-ray crystallography. Thus, mechanistic

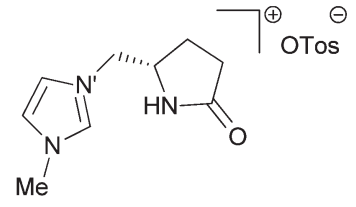

23

Fig. 5 Chiral bidentate uNHC precursor 23.

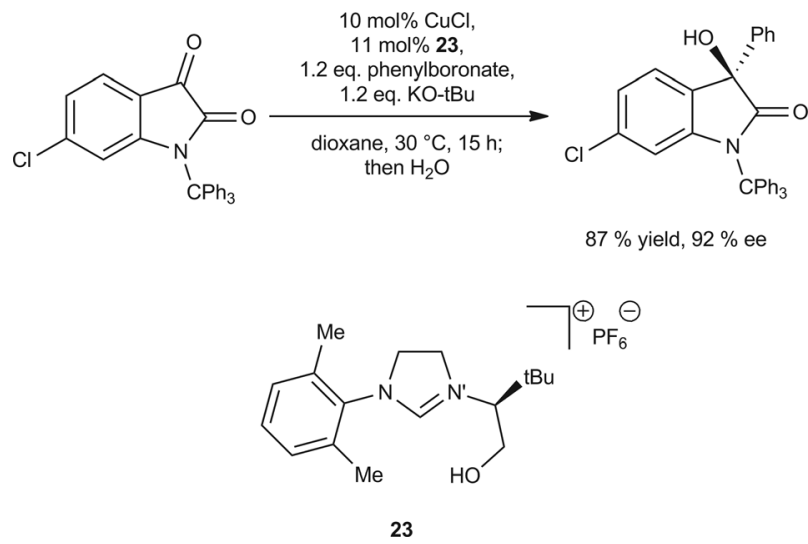

Scheme 11 Copper-mediated arylation of an isatin derivative employing 24.

studies that reveal structure-reactivity relationships for this kind of complexes are still rare.

A Rh-complex, generated in situ by using the amide-tethered uNHC precursor 23 (Fig. 5) ${ }^{41}$ was examined by the group of Vo-Thanh. It gives promising results in the asymmetric transfer hydrogenation of prochiral ketones; in these reactions, the highest enantioselectivities (up to $80 \%$ ee) for a catalyst that incorporates a chiral NHC were observed to the best of our knowledge. The reactivity and selectivity was dependent on the size of the $N$-substituent, whereas the least demanding methyl group provides the best results. By comparison with ligands based on core structures derived from thiazoles and triazoles, a strong dependency on the electronic properties was revealed, while the imidazole-derived uNHC $\mathbf{2 3}$ produced the most reactive species.

In 2010, Hayashi and coworkers introduced several uNHC precursors such as $\mathbf{2 4}$ (Scheme 11) that contain chiral $N^{\prime}$-alkoxy substituents. ${ }^{42}$ The in situ generated copper complexes are active in the 1,2-arylation of isatins using boronates as mild nucleophiles (Scheme 11). Combining ligand precursor 24 with $\mathrm{CuCl}$ yielded the product in $87 \%$ and with $92 \%$ ee. The strong donor properties of the free alcohol seem to be necessary for the formation of the active species in which the stereoinformation is efficiently transferred from the chiral center to the metal. This reasoning is supported by the observation that the incorporation of ether-tethered uNHCs results in low selectivities due to the diminished metal-donor interaction. The influence of the size of the stabilizing $N$-aryl moiety on the catalyst's performance was also investigated; the 2,6-dimethylphenyl group was found to be optimal. Decreasing or increasing the steric bulk led to reduced enantioselectivity. 
<smiles>CC(C)[PH2+][O-]</smiles>

25
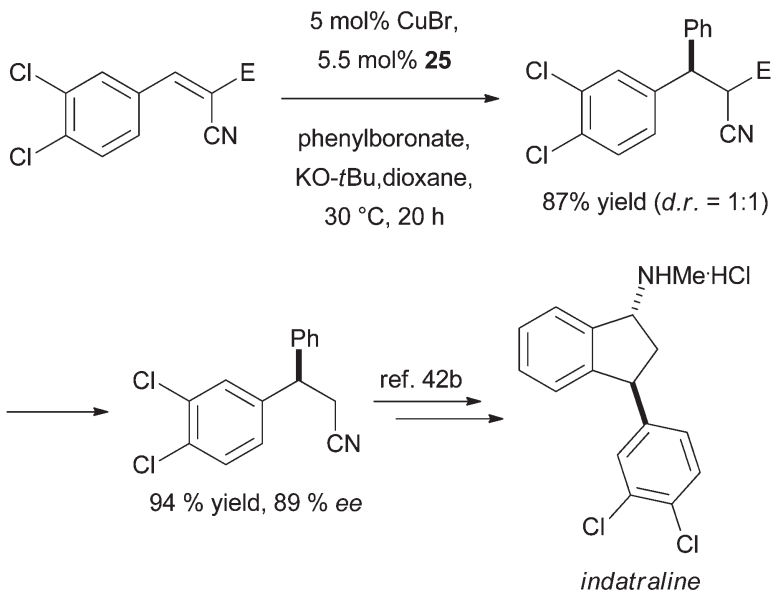

Scheme 12 1,4-Addition employing 25 in a key step of the total synthesis of indatraline $\left(\mathrm{E}=\mathrm{CO}_{2} \mathrm{CEt}_{3}\right)$.

Related systems were employed as ligand precursors in the copper-mediated conjugated addition of arylboronates to Michael systems (Scheme 12). The use of the rather bulky anthryl moiety as a symmetrical $N$-aryl group was found to be beneficial in terms of the enantioselectivity. Increasing the steric bulk of the stereogenic center located in the $N^{\prime}$-substituent on the other side of the uNHC and by integration in a more rigid cyclic system additionally improves the enantioselectivities. All these features are incorporated in $\mathbf{2 5}$. The utility of the corresponding $\mathrm{Cu}$-complex was demonstrated in the formation of a key intermediate within the total synthesis of the natural product indatraline. ${ }^{43 a, b}$ The stereogenic center was generated with $87 \%$ yield and after the removal of the ester, the ee was determined to amount to $89 \%$.

The group of Mauduit synthesized a series of hydroxyl-chelating uNHC precursors like $\mathbf{2 8},{ }^{44}$ which could be smoothly obtained in four steps (Scheme 13). Naphthyl amine 26 was acylated with ethyl oxalyl chloride, while subsequent amide formation with a chiral amino alcohol and reduction yields the corresponding diamine 27. After cyclization, the carbene precursor 28 was successfully obtained in good overall yields. Due to the variability of the introduced primary amines and amino alcohols a multiplicity of imidazolium salts, differing in both $\mathrm{N}$ - and $N^{\prime}$-substituents, were synthesized. The activity of the corresponding complexes in the copper-mediated conjugated addition of diethyl zinc to cyclohexenone was investigated and the focus was on the structure-activity relationship. With regard to the $N^{\prime}$ substituent bearing the hydroxyl-chelating donor, the influence of the position and the steric demand of the stereogenic group on the selectivity was examined. By installation of the stereocenter in the $\alpha$-position instead of the $\beta$-position, a better chirality transfer was obtained, thus resulting in higher enantiodiscrimination.

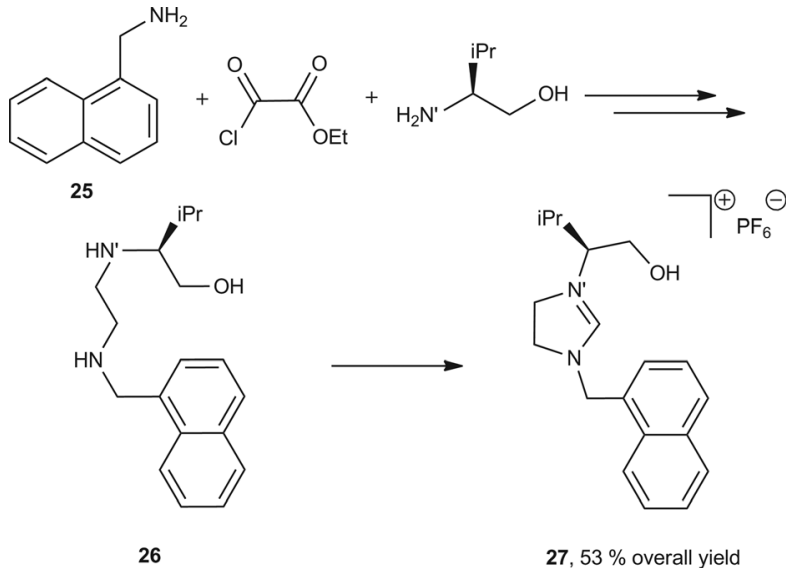

Scheme 13 Synthesis of the hydroxyl alkyl tethered uNHC precursor 28.

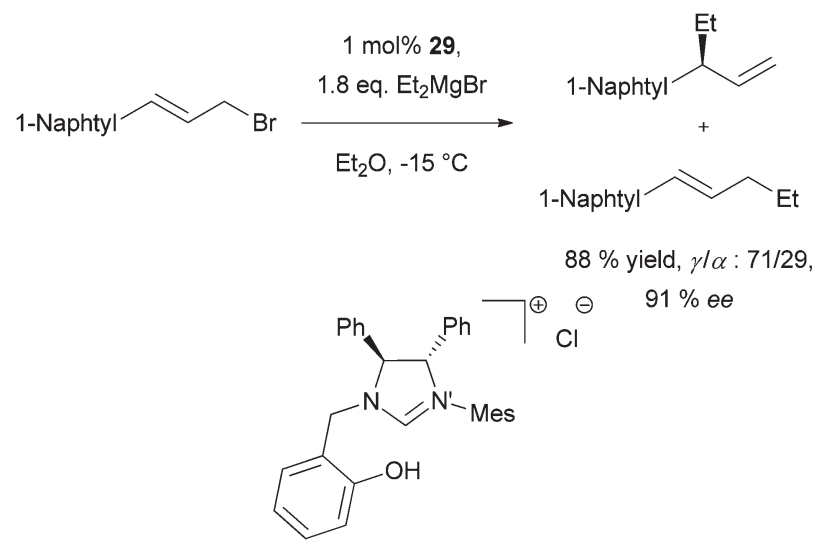

29

Scheme 14 Copper-free asymmetric allylic alkylation employing 29.

Enhanced steric bulk of this moiety led to diminished selectivities, and iso-butyl was found to be superior to tert-butyl. A decrease of the steric demand of the aryl group in the non-chelating $N$-substituent, e.g. by replacement of the bulky mesityl with a naphthyl group, was beneficial with regard to the observed ee values. $\mathbf{2 8}$ was shown to be the most successful ligand precursor employed in this series, mediating the 1,4-addition with a catalyst loading of $3 \mathrm{~mol} \%$ to full conversion, and with an ee of $92 \%$. Comparative experiments with related ligand structures bearing the stereogenic center in the backbone led to moderate enantioselectivities; an efficient transfer of chirality in the formed copper-species could not be accomplished via this type of hydroxyl tether.

Alexakis and coworkers investigated the catalytic properties of in situ formed magnesium complexes bearing uNHCs related to 29 where the chiral information is located in the backbone (Scheme 14). ${ }^{45}$ These complexes provide very good results in copper-free asymmetric allylic alkylation (AAA) reactions. The strong $\sigma$-donor character of the uNHC enhances the electron density at the metal atom and consequently the Grignard reagent's nucleophilicity, thus increasing the reactivity. A control experiment performed without addition of uNHC yielded the 
alkylation product in less than 5\%. The regioselectivity for this reaction type seems to be directed by the non-chelating $N^{\prime}$-substituent. In case of a benzyl-group employed, the favored formation of the $\alpha$ - instead of the $\gamma$-alkylated product is observed. The enantiodiscrimination was found to be dependent on the distance of the donor to the carbene center. Carbenes with four carbon atoms in the tether lead to lower selectivities in the AAA reaction with alkyl Grignard reagents than those with three atoms. Note that the actual tether length that is required for ideal coordination of the bidentate ligand depends on the choice of the metal center. uNHCs with sterically hindered hydroxyl groups result in lower ee's due to hampered chelation.

Also in the even more challenging transformation of allylic systems with trisubstituted double bonds to quarternary centers, the catalyst exhibits good enantiomeric excess up to $91 \%$ ee and similar trends in regioselectivity that, however, depends on the bulkiness of the substrate. The high $\gamma$-selectivity of up to $98: 2$ $\gamma / \alpha$ demonstrates the complementarity of this method as compared with the copper-catalyzed reactions, where $\alpha$-substitution is favored. ${ }^{46}$

Hoveyda and coworkers have investigated in situ generated copper-complexes derived from uNHC precursors such as $\mathbf{3 0}$ (Fig. 6). ${ }^{47 a-h}$ In hydroboration reactions, these catalysts feature higher activity when compared with catalysts bearing symmetrical chiral NHCs. The stereoinformation within the disubstituted backbone of the carbene ligand is predominantly transferred to the metal center via the chelating $N$-substituent. The less Lewis basic character (sulfonates compared to alcoholates, for example) of the coordinating group was shown to be crucial for efficient chirality transfer. ${ }^{46,48}$ The rigid chelation of the metal center by the sulfonate causes a strong torsion of the aryl-N bond. Therefore the steric repulsion of the hydrogen atom in the orthoposition of the $N$-aryl group with the backbone substituent is efficiently minimized in this conformation, in which the sulfonate group is orientated syn to the stereogenic phenyl group. As a consequence of these steric relations, the conformation of the coordinating tether in the complex is opposite to the one observed in the uNHC precursor 30. ${ }^{47 h}$ An unsymmetrical noncoordinating $N^{\prime}$-aryl substituent on the other side of the uNHC further improves the selectivity. Increasing the steric bulk at the ortho-position results in a more severe tilting, thus allowing the accommodation of the substrate in a well-defined fashion and consequently an enhanced reactivity. The catalyst derived from 30 was found to be superior for the hydroboration of bulky $\alpha$-substituted styrenes in up to $93 \%$ ee. ${ }^{47 h}$ This ligand type was also employed in $\mathrm{Zn}$ - and Al-based complexes, showing the same structure-reactivity relationship. ${ }^{46}$ In the copper-free enantioselective allylic alkylation reaction of either diethyl zinc or trimethyl aluminum with linear allyl phosphonates, high

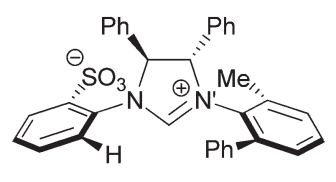

30

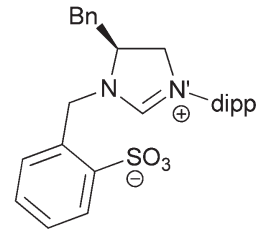

31
Fig. 6 Sulfonate-tethered uNHC precursors $\mathbf{3 0}$ and $\mathbf{3 1 .}$ reactivities are observed, yielding the corresponding products in excellent $\gamma$-selectivities and up to $94 \%$ ee. $^{46}$

The stereoinformation within the disubstituted backbone of the catalysts derived from carbene precursors such as $\mathbf{3 1}$ (Fig. 6) were introduced by the group of Woodward as highly active species in the asymmetric $\gamma$-selective reaction of allylic halides with Grignard reagents, in order to avoid the use of transition metals. ${ }^{49}$ Cinnamoyl bromides were alkylated with excellent regioselectivities and ee's up to $82 \%$. The chirality is located in the monosubstituted backbone of the uNHC, and the enantioinduction was most efficient for benzyl as the stereogenic group. The presence of the sulfonate donor in the $N$-substituent gives rise to complexes that show significant enantiodiscriminations. When the steric bulk of the coplanar non-coordinating $N^{\prime}$-aryl substituent is increased by the introduction of dipp, for example, both the regio- and the enantioselectivity are improved. The decreased selectivities that are observed for more bulky $\alpha$-methyl substrates indicate that the binding to the metal center is hindered, and this effect is presumably caused by the crowded coordination sphere.

\section{Tridentate achiral uNHCs in metal catalysis}

The additional chelatization provided by tridentate ligands can result in an improved stabilization of the precatalyst. ${ }^{50 a, b}$ Furthermore, the use of hemilabile donors gives rise to the formation of robust and catalytically active species. ${ }^{51} \mathrm{Ni}$-complex 32, for example, that bears a tridentate $C, N, N$-pincer ligand (Scheme 15) was investigated by the group of Wang in Kumadaas well as in Negishi-cross coupling reactions. ${ }^{52} 32$ was synthesized in four steps, starting with azidophenyl imidazole 33; treatment with isopropyl iodide affords the corresponding imidazolium salt, and the subsequent reaction with bis(diphenylphosphino)methane as well as the addition of tolyl azide gives rise to the carbene precursor 34. Deprotonation with $n-B u L i$ and ligand exchange with $\mathrm{NiCl}_{2}(\mathrm{dme})$ generates 32. The strained ligand causes a distortion of the square planar coordination sphere, and this geometric constraint is important for preventing catalyst decomposition via reductive elimination of the ligand. ${ }^{39}$ The dynamic dissociation behavior of the terminally bound nitrogen donor facilitates the formation of a coordinatively unsaturated active catalyst. The ease of generating a free coordination site for

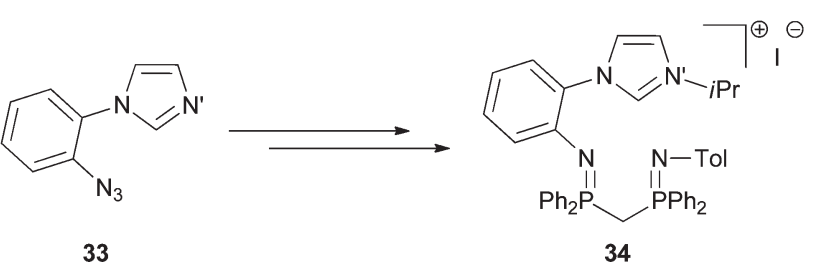

33

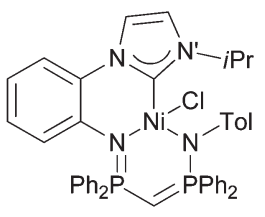

$32,33 \%$ yield

Scheme 15 Synthesis of Ni-based precatalyst 32. 


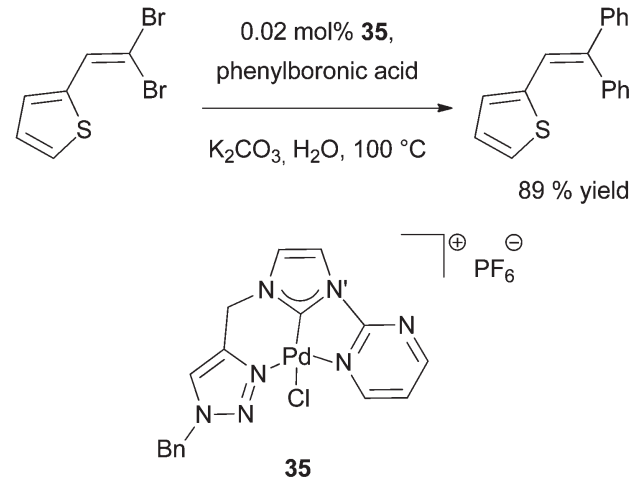

Scheme 16 Double Suzuki-Miyaura reaction of a geminal dibromo compound accomplished by $\mathbf{3 5}$.

the substrate entrance combined with the strong $\sigma$-donating properties of the carbene promotes the oxidative addition of the aryl halide, thus resulting in a high catalytic performance. Consequently 32 exhibits high reactivity in Negishi reactions, coupling aryl chlorides with aryl-zinc compounds in excellent yields employing catalyst loadings down to $0.05 \mathrm{~mol} \%$. Furthermore, 32 promotes Kumada reactions by using less reactive aryl chlorides as well.

The group of Chen synthesized palladium-based complexes of type 35 (Scheme 16) ${ }^{53}$ The incorporated tridentate $N, C, N$-pincer ligands feature pyrimidin and triazole substituents as coordinating donors. This precatalyst is stable under air for months without decomposition. 35 was found to efficiently promote aqueous Suzuki-Miyaura cross coupling reactions under air with catalyst loadings down to $0.01 \mathrm{~mol} \%$, thus reflecting the robustness and high reactivity of this metal complex. Differing from common applications, a double Suzuki-Miyaura reaction employing a broad range of geminal dibromo vinyl compounds was explored using $\mathbf{3 5}$ as precatalyst (Scheme 16).

\section{Tridentate chiral uNHCs in metal catalysis}

The enhanced rigidity of tridentate ligands can be beneficial for an efficient transfer of chirality. However, the synthesis and employment of chiral tridentate uNHC ligands is only sparsely discussed. ${ }^{54 a, b}$ The group of Sakaguchi introduced various functionalized ligands of type $\mathbf{3 6}$ (Fig. 7), ${ }^{55 a, b}$ which are active in the copper-catalyzed alkylation of cyclic $\alpha, \beta$-unsaturated ketones with zinc organyls. In comparative experiments using alcoholand ester-tethered catalytically active species, significantly improved enantioselectivities were observed with the alcoholtethered ligand. Due to the enhanced donor properties, the chiral information of the stereogenic center in proximity to the metal center is efficiently transferred. The alkylated products were obtained with up to $99 \%$ ee in moderate to excellent yields. Exploring the influence of the $\mathrm{N}$-substituent and the stereogenic group on the performance of the catalyst was neglected and constitutes a challenge for future developments.

\section{Conclusion}

In various research areas it was discovered that metal species which bear uNHCs exhibit superior performance as compared

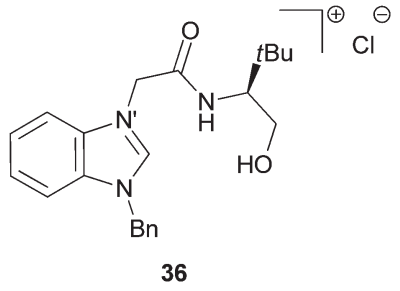

Fig. $7 \quad 36$ as example for a tridentate chiral ligand.

with their symmetrical equivalents. Thus, uNHCs constitute valuable ligands for metal-catalyzed reactions. Some topics are well-investigated, and tailor-made systems for specific transformations are already available. Nonetheless, others still furnish challenging problems, which might be accomplished by the use of catalysts bearing uNHCs. Understanding the structure-reactivity relationship of complexes of this type is essential for the development of new concepts in ligand design. Versatile routes exist for the synthesis of uNHCs and numerous modifications are possible, thus allowing the establishment of large libraries of potentially useful structures. The new catalysts featuring these uNHCs offer perspectives for metal-mediated processes, combining enhanced stability, increased reactivity and remarkable selectivity.

\section{References}

1 H. W. Wanzlick and H. J. Kleiner, Angew. Chem., 1961, 73, 493.

2 M. F. Lappert, J. Organomet. Chem., 1988, 358, 185.

3 A. J. Arduengo, R. L. Harlow and M. Kline, J. Am. Chem. Soc., 1991, $113,361$.

4 (a) O. Navarro and M. S. Viciu, Annu. Rep. Prog. Chem., Sect. B, 2011, 107, 226; (b) T. Suzuki, Chem. Rev., 2011, 111, 1825; (c) G. C. Fortman and S. P. Nolan, Chem. Soc. Rev., 2011, 40, 5151; (d) W. Gil and A. M. Trzeciak, Coord. Chem. Rev., 2011, 255, 473; (e) G. C. Vougioukalakis and R. H. Grubbs, Chem. Rev., 2010, 110, 1746; (f) O. Navarro and M. S. Viciu, Annu. Rep. Prog. Chem., Sect. B, 2010, 106, 243; (g) Y.-M. He and Q.-H. Fan, Org. Biomol. Chem., 2010, 8, 2497; (h) M. Poyatos, J. A. Mata and E. Peris, Chem. Rev., 2009, 109, 3677; (i) S. Díez-González, N. Marion and S. P. Nolan, Chem. Rev., 2009, 109, 3612; (j) X. Bantreil, J. Broggi and S. P. Nolan, Annu. Rep. Prog. Chem., Sect. B, 2009, 105, 232; (k) C. Samojlowicz, M. Bieniek and K. Grela, Chem. Rev., 2009, 109, 3708; (l) F. E. Hahn and M. C. Jahnke, Angew. Chem., Int. Ed., 2008, 47, 3122; (m) J. M. Praetorius, D. P. Allen, R. Wang, J. D. Webb, F. Grein, P. Kennepohl and C. M. Crudden, J. Am. Chem. Soc., 2008, 130, 3724; (n) P. L. Arnold and S. Pearson, Coord. Chem. Rev., 2007, 251, 596.

5 R. M. Thomas, B. K. Keitz, T. M. Champagne and R. H. Grubbs, J. Am. Chem. Soc., 2011, 133, 7490.

6 S. H. Hong, A. G. Wenzel, T. T. Salguero, M. W. Day and R. H. Grubbs, J. Am. Chem. Soc., 2007, 129, 7961.

7 (a) A. S. K. Hashmi, C. Lothschuetz, C. Boehling, T. Hengst, C. Hubbert and F. Rominger, Adv. Synth. Catal., 2010, 352, 3001; (b) A. S. K. Hashmi, C. Lothschuetz, C. Boehling and F. Rominger, Organometallics, 2011, 30, 2411; (c) A. S. K. Hashmi, Y. Yu and F. Rominger, Organometallics, 2012, 31, 895.

8 M. J. Spallek, D. Riedel, F. Rominger, A. S. K. Hashmi and O. Trapp, Organometallics, 2012, 31, 1127.

9 C. Dash, M. M. Shaikh and P. Ghosh, Eur. J. Inorg. Chem., 2009, 1608.

10 C. J. O’Brien, E. A. B. Kantchev, C. Valente, N. Hadei, G. A. Chass, A. Lough, A. C. Hopkinson and M. G. Organ, Chem.-Eur. J., 2006, 12, 4743.

11 T. Nakamura, T. Terashima, K. Ogata and S.-i. Fukuzawa, Org. Lett., 2011, 13, 620.

12 S. Hohloch, C.-Y. Su and B. Sarkar, Eur. J. Inorg. Chem., 2011, 3067. 
13 Selected example for a clickreaction of sterically demanding substrates: C. W. Tornøe, C. Christensen and M. Meldal, J. Org. Chem., 2002, 67, 3057.

14 J. K. Park, H. H. Lackey, M. D. Rexford, K. Kovnir, M. Shatruk and D. T. McQuade, Org. Lett., 2010, 12, 5008.

15 Further examples for catalysts with ring expanded uNHCs: (a) E. L. Kolychev, I. A. Portnyagin, V. V. Shuntikov, V. N. Khrustalev and M. S. Nechaev, J. Organomet. Chem., 2009, 694, 2454; (b) A. Binobaid, M. Iglesias, D. J. Beetstra, B. Kariuki, A. Dervisi, I. A. Fallis and K. J. Cavell, Dalton Trans., 2009, 7099.

16 J. K. Park, H. H. Lackey, B. A. Ondrusek and D. T. McQuade, J. Am. Chem. Soc., 2011, 133, 2410

17 (a) A. Kannenberg, D. Rost, S. Eibauer, S. Tiede and S. Blechert, Angew. Chem., Int. Ed., 2011, 50, 3299; (b) S. Tiede, A. Berger, D. Schlesiger, D. Rost, A. Lühl and S. Blechert, Angew. Chem., Int. Ed., 2010, 49, 3972; (c) J. Savoie, B. Stenne and S. K. Collins, Adv. Synth. Catal., 2009, 351, 1826; (d) J. M. Berlin, S. D. Goldberg and R. H. Grubbs, Angew. Chem., Int. Ed., 2006, 45, 7591.

18 K.-s. Lee and A. H. Hoveyda, J. Org. Chem., 2009, 74, 4455.

19 E. M. Vieira, M. L. Snapper and A. H. Hoveyda, J. Am. Chem. Soc., 2011, 133, 3332 .

20 P.-A. Fournier and S. K. Collins, Organometallics, 2007, 26, 2945.

21 B. Stenne, J. Timperio, J. Savoie, T. Dudding and S. K. Collins, Org. Lett., 2010, 12, 2032.

22 See also: S. Kreß and S. Blechert, Chem. Soc. Rev., 2012, DOI: 10.1039/ c2cs15348c.

23 R. E. Meléndez and W. D. Lubell, Tetrahedron, 2003, 59, 2581.

24 (a) K. Vehlow, S. Gessler and S. Blechert, Angew. Chem., Int. Ed., 2007, 46, 8082; (b) C. K. Chung and R. H. Grubbs, Org. Lett., 2008, 10, 2693.

25 S. Blechert and coworkers, unpublished work.

26 (a) S. Randl, S. Gessler, H. Wakamatsu and S. Blechert, Synlett, 2001, 3, 430; (b) P. Liu, X. Xu, X. Dong, B. K. Keitz, M. B. Herbert, R. H. Grubbs and K. N. Houk, J. Am. Chem. Soc., 2012, 134, 1464; (c) B. K. Keitz, K. Endo, P. R. Patel, M. B. Herbert and R. H. Grubbs, J. Am. Chem. Soc., 2012, 134, 693.

27 K. Endo and R. H. Grubbs, J. Am. Chem. Soc., 2011, 133, 8525.

28 T. M. Trnka, J. P. Morgan, M. S. Sanford, T. E. Wilhelm, M. Scholl, T.L. Choi, S. Ding, M. W. Day and R. H. Grubbs, J. Am. Chem. Soc., 2003, 125, 2546

29 H. Jullien, D. Brissy, R. Sylvain, P. Retailleau, J.-V. Naubron, S. Gladiali and A. Marinetti, Adv. Synth. Catal., 2011, 353, 1109.

30 D. Brissy, M. Skander, P. Retailleau, G. Frison and A. Marinetti, Organometallics, 2009, 28, 140.

31 W. D. Kerber, J. H. Koh and M. R. Gagné, Org. Lett., 2004, 6, 3013.

32 D. Brissy, M. Skander, H. Jullien, P. Retailleau and A. Marinetti, Org. Lett., 2009, 11, 2137.

33 S. C. Sau, S. Santra, T. K. Sen, S. K. Mandal and D. Koley, Chem Commun., 2012, 48, 555.

34 (a) G. Ung and G. Bertrand, Chem.-Eur. J., 2011, 17, 8269; (b) M. Heckenroth, A. Neels, M. G. Garnier, P. Aebi, A. W. Ehlers and M. Albrecht, Chem.-Eur. J., 2009, 15, 9375.
35 (a) B. Krebs and G. Henkel, Angew. Chem., Int. Ed. Engl., 1991, 30, 769; (b) D. Yuan and H. V. Huynh, Organometallics, 2010, 29, 6020.

36 M. Bassetti, Eur. J. Inorg. Chem., 2006, 4473.

37 (a) S. Warsink, P. Hauwert, M. A. Siegler, A. L. Spek and C. J. Elsevier, Appl. Organomet. Chem., 2009, 23, 225; (b) S. Warsink, S. Bosman, J. J. Weigand and C. J. Elsevier, Appl. Organomet. Chem., 2011, 25, 276; (c) S. Warsink, C. M. S. van Aubel, J. J. Weigand, S.-T. Liu and C. J. Elsevier, Eur. J. Inorg. Chem., 2010, 5556; (d) S. Warsink, R. M. Drost, M. Lutz, A. L. Spek and C. J. Elsevier, Organometallics, 2010, 29, 3109; (e) S. Warsink, I. H. Chang, J. J. Weigand, P. Hauwert, J.T. Chen and C. J. Elsevier, Organometallics, 2010, 29, 4555.

38 (a) D. Meyer, M. A. Taige, A. Zeller, K. Hohlfeld, S. Ahrens and T. Strassner, Organometallics, 2009, 28, 2142; (b) D. Meyer, A. Zeller and T. Strassner, J. Organomet. Chem., 2012, 701, 56.

39 A. T. Normand and K. J. Cavell, Eur. J. Inorg. Chem., 2008, 2781.

40 M. L. Rosenberg, A. Krivokapic and M. Tilset, Org. Lett., 2009, 11, 547.

41 A. Aupoix, C. Bournaud and G. Vo-Thanh, Eur. J. Org. Chem., 2011, 2772.

42 R. Shintani, K. Takatsu and T. Hayashi, Chem. Commun., 2010, 46, 6822.

43 (a) K. Takatsu, R. Shintani and T. Hayashi, Angew. Chem., Int. Ed., 2011, 50, 5548; (b) H. M. L. Davies and T. M. Gregg, Tetrahedron Lett., 2002, 43, 4951.

44 D. Rix, S. Labat, L. Toupet, C. Crévisy and M. Mauduit, Eur. J. Inorg. Chem., 2009, 1989.

45 O. Jackowski and A. Alexakis, Angew. Chem., Int. Ed., 2010, 49, 3346.

46 Y. Lee, B. Li and A. H. Hoveyda, J. Am. Chem. Soc., 2009, 131, 11625.

47 (a) R. Corberan, N. W. Mszar and A. H. Hoveyda, Angew. Chem., Int. $E d$., 2011, 50, 7079; (b) Y. Lee, H. Jang and A. H. Hoveyda, J. Am. Chem. Soc., 2009, 131, 18234; (c) B. Jung and A. H. Hoveyda, J. Am. Chem. Soc., 2012, 134, 1490; (d) F. Gao, Y. Lee, K. Mandai and A. H. Hoveyda, Angew. Chem., Int. Ed., 2010, 49, 8370; (e) K. Akiyama, F. Gao and A. H. Hoveyda, Angew. Chem., Int. Ed., 2010, 49, 419; (f) R. Shintani, K. Takatsu, M. Takeda and T. Hayashi, Angew. Chem., Int. Ed., 2011, 50, 8656; $(g)$ F. Gao, K. P. McGrath, Y. Lee and A. H. Hoveyda, J. Am. Chem. Soc., 2010, 132, 14315; (h) A. Guzman-Martinez and A. H. Hoveyda, J. Am. Chem. Soc., 2010, 132, 10634.

48 M. K. Brown, T. L. May, C. A. Baxter and A. H. Hoveyda, Angew. Chem., Int. Ed., 2007, 46, 1097.

49 C. M. Latham, A. J. Blake, W. Lewis, M. Lawrence and S. Woodward, Eur. J. Org. Chem., 2012, 699.

50 (a) D. Pugh and A. A. Danopoulos, Coord. Chem. Rev., 2007, 251, 610; (b) E. Peris and R. H. Crabtree, Coord. Chem. Rev., 2004, 248, 2239.

51 B. Pierre, J. Organomet. Chem., 2004, 689, 3953.

52 C. Zhang and Z.-X. Wang, Organometallics, 2009, 28, 6507.

53 S. Gu, H. Xu, N. Zhang and W. Chen, Chem.-Asian J., 2010, 5, 1677.

54 (a) The Chemistry of Pincer-Compounds, ed. D. Morales-Morales and C. M. Jensen, Elsevier, Amsterdam, 2007; (b) P. D. Newman, K. J. Cavell, A. J. Hallett and B. M. Kariuki, Dalton Trans., 2011, 40, 8807.

55 (a) M. Yoshimura, N. Shibata, M. Kawakami and S. Sakaguchi, Tetrahedron, 2012, 68, 3512; (b) N. Shibata, M. Okamoto, Y. Yamamoto and S. Sakaguchi, J. Org. Chem., 2010, 75, 5707. 